\title{
Qualidade de sementes de pitombeira em função do período e da temperatura de secagem
}

\section{Talisia esculenta seed quality in function of drying temperatures and times}

\author{
Edson de Almeida Cardoso ${ }^{1}$; Edna Ursulino Alves ${ }^{2}$; Adriana Ursulino Alves ${ }^{3 *}$
}

\section{Resumo}

A pitombeira (Talisia esculenta Radlk) é uma espécie da família Sapindaceae nativa da Região amazônica, cujos frutos são obtidos principalmente de forma extrativista e sua propagação é realizada por meio de sementes, as quais são do tipo recalcitrante, ou seja, de baixa longevidade e sensíveis à dessecação. Dessa forma, o objetivo foi avaliar o efeito de diferentes métodos para secagem de sementes de T. esculenta. As sementes foram postas para secar em estufa com circulação de ar forçado, nas temperaturas de 40,45 e $50^{\circ} \mathrm{C}$ por períodos de $0,6,12,24,30$ e 36 horas. O delineamento experimental foi inteiramente ao acaso, em esquema fatorial $3 \times 7$ (três temperaturas $\mathrm{x}$ sete períodos de secagem), em quatro repetições de 25 sementes cada; os dados foram submetidos a análise de variância e de regressão polinomial, ao nível de 5\% de probabilidade de erro. A avaliação do efeito dos tratamentos foi realizada mediante determinação do teor de água, primeira contagem e porcentagem de emergência de plântulas, índice de velocidade de emergência e comprimento e massa seca de plântulas. Para garantir a qualidade, a secagem das sementes de Talisia esculenta Radlk deve ser realizada nas temperaturas de 40 e $45^{\circ} \mathrm{C}$ por um período inferior a seis horas, quando atingem $41 \%$ de umidade.

Palavras-chave: Recalcitrante, frutífera nativa, longevidade, dessecação

\begin{abstract}
Talisia esculenta Radlk is a species of the Sapindaceae family native to the Amazon region. Its fruits are principally obtained by collecting in natura; its propagation is by seeds, which are of the recalcitrant type, with low longevity and sensitivity to dehydration. We evaluated the effects of different drying times and temperatures on T. esculenta seeds. The seeds were dried in a forced-air oven at 40, 45, and $50^{\circ} \mathrm{C}$ for periods of $0,6,12,24,30$, and 36 hours, using four replications of 25 seeds each. Tests were conducted to determine seed quality: moisture contents, emergence percentage, first counts, emergence speed index and the length and dry weight of the seedlings. The data was submitted to analysis of variance and polynomial regression, at a $5 \%$ level of probability. T. esculenta seeds should be dried at 40 or $45^{\circ} \mathrm{C}$ for no more than six hours for best initial seedling growth.
\end{abstract}

Key words: Recalcitrant seeds, "Pitomba", longevity, desiccation

\footnotetext{
${ }^{1}$ Eng $^{\circ}$ Agr $^{\circ}$, M.e, Discente do Curso de Doutorado do PPGA em Agronomia, Universidade Federal da Paraíba, UFPB, Centro de Ciências Agrárias, CCA, Areia, PB. Bolsistas da CAPES. E-mail: edsonagro@hotmail.com; edsonagronomia@outlook.com

${ }^{2}$ Eng $^{\mathrm{a}}$ Agr $^{\mathrm{a}}$, Prof $^{\mathrm{a}}$ Dr $^{\mathrm{a}}$, Dept ${ }^{\mathrm{o}}$ de Fitotecnia, Universidade Federal da Paraíba, UFPB, Centro de Ciências Agrárias, CCA, Areia, PB. E-mail: ednaursulino@cca.ufpb.br

${ }^{3}$ Eng $^{\mathrm{a}}$ Agr $^{\mathrm{a}}$, Prof ${ }^{\mathrm{a}}$ Dr $^{\mathrm{a}}$, Dept ${ }^{\mathrm{o}}$ de Engenharias, Universidade Federal do Piauí, UFPI, Campus Prof. ${ }^{\mathrm{a}}$ Cinobelina Elvas, CPCE, Bom Jesus, PI. E-mail: adrianaursulino@ufpi.edu.br

* Autor para correspondência
} 


\section{Introdução}

A pitombeira (Talisia esculenta Radlk), da família Sapindaceae, é uma espécie nativa da região amazônica, sendo encontrada no interior de matas densas primárias, bem como em formações secundárias, mas sempreem várzeas aluviais e fundos de vales, principalmente em áreas de transição de Cerrado e Caatinga, nas regiões Norte, Nordeste e Sudeste do Brasil. Essa frutífera é de porte arbóreo, que chega a atingir de 6 a 12 metros de altura e, tronco entre 30 e $40 \mathrm{~cm}$ de diâmetro (GUARIM NETO; SANTANA; SILVA, 2003). Ainda segundo os autores, os frutos são quase globosos, granulados, apiculados e pouco pubescentes, pulverulentos, amarelados e com resíduos do cálice, geralmente monospérmicos. As sementes são alongadas, com testas avermelhadas, logo após a retirada dos frutos, e escuras quando secas, envolvidas por arilo róseoesbranquiçado e comestível.

A espécie tem grande importância ecológica devido à dispersão ornitocórica (VIEIRA; GUSMÃO, 2008) e importância econômica, pois os frutos e produtos derivados são muito utilizados na culinária regional. A polpa é utilizada in natura e na fabricação de compotas, geléias e doces em massa, e o sabor assemelha-se ao do damasco (Prunus armeniaca L.) (GUARIM NETO; SANTANA; SILVA, 2003).

A propagação da $T$. esculenta é por meio de sementes, as quais têm curta longevidade, sendo necessária à semeadura logo após a extração dos frutos. Esta espécie é considerada recalcitrante, ou seja, a redução da umidade pode ocasionar danos, prejudicando sua viabilidade e vigor, resultando até em sua morte (LORENZI; MATOS, 2006). Esse comportamento das sementes pode ser considerado como resultado do processo de seleção natural, em concordância com as condições ambientais das regiões de origem da espécie (KERMODE, 1990; BARBEDO; MARCOS FILHO, 1998).

Nas sementes recalcitrantes, de forma geral, em nenhum momento do desenvolvimento se verifica tolerância à dessecação, motivo pelo qual há grande dificuldade em sua conservação (HARTMANN et al., 2001), uma vez que a perda de água, durante o processo de secagem, pode causar alteração de sistemas metabólicos e de membranas resultando na deterioração das sementes (PAMMENTER; BERJAK, 1999). Os distúrbios metabólicos podem ser provenientes do aumento da concentração de solutos (sais, aminoácidos, açúcares), o que altera a força iônica e o pH da solução intracelular, levando à desnaturação irreversível de proteínas (NEDEVA; NIKOLOVA, 1997).

Uma vez que as sementes recalcitrantes possuem teores de água definidos como críticos, abaixo dos quais a viabilidade é reduzida, também há teores de água letais, relacionados à perda total da viabilidade (PRITCHARD, 1991; HONG; ELLIS, 1992; BILIA; MARCOS-FILHO; NOVEMBRE, 1999). Valores entre 27 a $38 \%$ para o teor de água crítico e entre 12 a $22 \%$ para o teor de água letal foram reportados para sementes de Euterpe edulis Mart. e Inga uruguensis Hook. etArn. (ANDRADE; PEREIRA, 1997; BILIA; MARCOS-FILHO; NOVEMBRE, 1999). Para sementes Cinnamomum zeylanicum Ness, teores de água inferiores a $34,82 \%$ proporcionaram redução significativa na porcentagem e velocidade de germinação (SILVA et al., 2012). Portanto, o conhecimento dos teores de água crítico e letal para sementes de uma espécie é indispensável para o planejamento e a execução da secagem e do armazenamento das mesmas.

Desta forma, este trabalho teve por objetivo avaliar o efeito de diferentes períodos e temperaturas para secagem de sementes de T. esculenta.

\section{Material e Métodos}

O experimento foi conduzido no Laboratório de Análise de Sementes (LAS) do Centro de Ciências Agrárias da Universidade Federal da Paraíba (CCA/ UFPB), em Areia-PB. Para os frutos de pitombeira ( $T$. esculenta) utilizados e caracterizados pela coloração marrom-escura (ALVES et al., 2008b) foram 
realizadas três colheitas diretamente das mesmas 15 árvores matrizes localizadas no município de Areia. As três colheitas foram necessárias porque se utilizou a mesma estufa para evitar que ocorressem interferências do aparelho adotado no experimento, uma vez que foram três temperaturas de secagem.

Após as colheitas, os frutos foram levados para o LAS, onde as sementes foram extraídas mediante abertura manual dos mesmos. Em seguida as sementes de $T$. esculenta foram postas para fermentar em baldes plásticos contendo água, por um período de cinco dias, determinados em ensaios prévios. Ao término da fermentação, estas foram lavadas em água corrente friccionado-as umas as outras sobre peneiras para retirada do arilo, uma vez que este dificulta a germinação das sementes. Após esses procedimentos, quatro repetições de 25 sementes foram retiradas e semeadas imediatamente (período zero, denominado controle sem secagem) e, as outras foram colocadas sobre papel toalha para retirada do excesso de umidade e submetidas à secagem em estufa com circulação e renovação de ar forçado, nas temperaturas de 40,45 e $50^{\circ} \mathrm{C}$, pelos períodos de $6,12,24,30$ e 36 horas, sendo estas submetidas ao delineamento experimental inteiramente ao acaso, em esquema fatorial $3 \times 7$ (três temperaturas $\mathrm{x}$ sete períodos de secagem), em quatro repetições de 25 sementes cada. A avaliação do efeito dos tratamentos foi realizada mediante determinação do teor de água, testes de emergência de plântulas e vigor (primeira contagem de sementes emergidas (\%) e índice de velocidade de emergência, bem como comprimento e massa seca de plântulas).

Teor de água - determinado em estufa regulada a $105 \pm 3^{\circ} \mathrm{C}$, (BRASIL, 2009) modificado, com quatro repetições com 10 sementes cada, cujos resultados foram expressos em porcentagem, em base úmida.

Emergência de plântulas - para cada tratamento utilizou-se 100 sementes, as quais foram divididas em quatro repetições de 25 , cuja semeadura foi realizada entre areia, em bandejas de plástico com dimensões de $49 \times 33 \times 7 \mathrm{~cm}$. A umidade do substrato areia lavada e esterilizada em autoclave foi mantida por meio de regas diárias com regador manual. As bandejas permaneceram em casa de crescimento (sem controle de temperatura e umidade) e as contagens foram realizadas diariamente, dos 17 aos 36 dias após a instalação do teste, quando se observou estabilização na emergência das plântulas. O critério de emergência utilizado foi o de plântulas com o epicótilo acima do nível do substrato e, os resultados foram expressos em porcentagem.

Primeira contagem de emergência - a primeira contagem foi conduzida juntamente com o teste de emergência de plântulas, cuja avaliação foi realizada aos 17 dias após a semeadura.

Índice de velocidade de emergência de plântulas (IVE) - determinado conjuntamente com o teste de emergência, mediante contagens diárias das plântulas normais emergidas até os 36 dias após a semeadura, cujo índice foi determinado de acordo com a fórmula proposta por Maguire (1962).

Comprimento e massa seca de plântulas - no final do teste de emergência, as plântulas normais de cada tratamento e repetição foram submetidas a medições com o auxílio de uma régua graduada em centímetros, sendo os resultados expressos em centímetros. Logo após as medições, as plântulas foram acomodadas em sacos de papel do tipo Kraft e levadas à estufa regulada a $65^{\circ} \mathrm{C}$ até atingir massa constante (48 horas) e, decorrido esse período, pesadas em balança analítica com precisão de 0,001 g (NAKAGAWA, 1999), sendo os resultados foram expressos em cm/plântula e g/plântula, respectivamente.

Delineamento experimental e análise estatística - a análise estatística dos dados foi realizada utilizando o delineamento experimental inteiramente ao acaso, em esquema fatorial $3 \times 7$ (três temperaturas $\mathrm{x}$ sete períodos de secagem), em quatro repetições de 25 sementes cada; os dados foram submetidos à análise de variância e de regressão polinomial, ao nível de $5 \%$ de probabilidade de erro. 


\section{Resultados e Discussão}

O teor de água das sementes de T. esculenta inicialmente era de 44,$0 ; 41,0$ e $46,0 \%$ nas temperaturas de 40,45 e $50^{\circ} \mathrm{C}$, respectivamente, diminuindo nas primeiras horas de secagem, atingindo 41,0; 40,0 e 41,0\% após seis horas de secagem e chegando a 36,$0 ; 34,0$ e $32,0 \%$ nas temperaturas de 40,45 e $50^{\circ} \mathrm{C}$, respectivamente, após 36 horas de secagem (Figura 1). Assim, observa-se redução no teor de água das sementes com o aumento do tempo de secagem. Analisando a taxa de redução nos teores de água em relação ao aumento do tempo de secagem constata-se que houve uma redução de 6, 2 e 9\% com seis horas de secagem e, 18,$0 ; 17,0$ e 30,0\% com 36 horas de secagem nas temperaturas de 40,45 e $50^{\circ} \mathrm{C}$, respectivamente. Diante dos resultados verificase que os teores de água situariam as sementes de T. esculenta entre as mais sensíveis à dessecação, segundo a classificação de Farrant, Pammenter e Berjak (1988), cujos critérios baseiam-se na redução drástica da viabilidade e vigor a medida que o teor de água é reduzido.

Figura 1. Teor de água de sementes de T. esculenta em função de diferentes períodos e temperaturas de secagem.

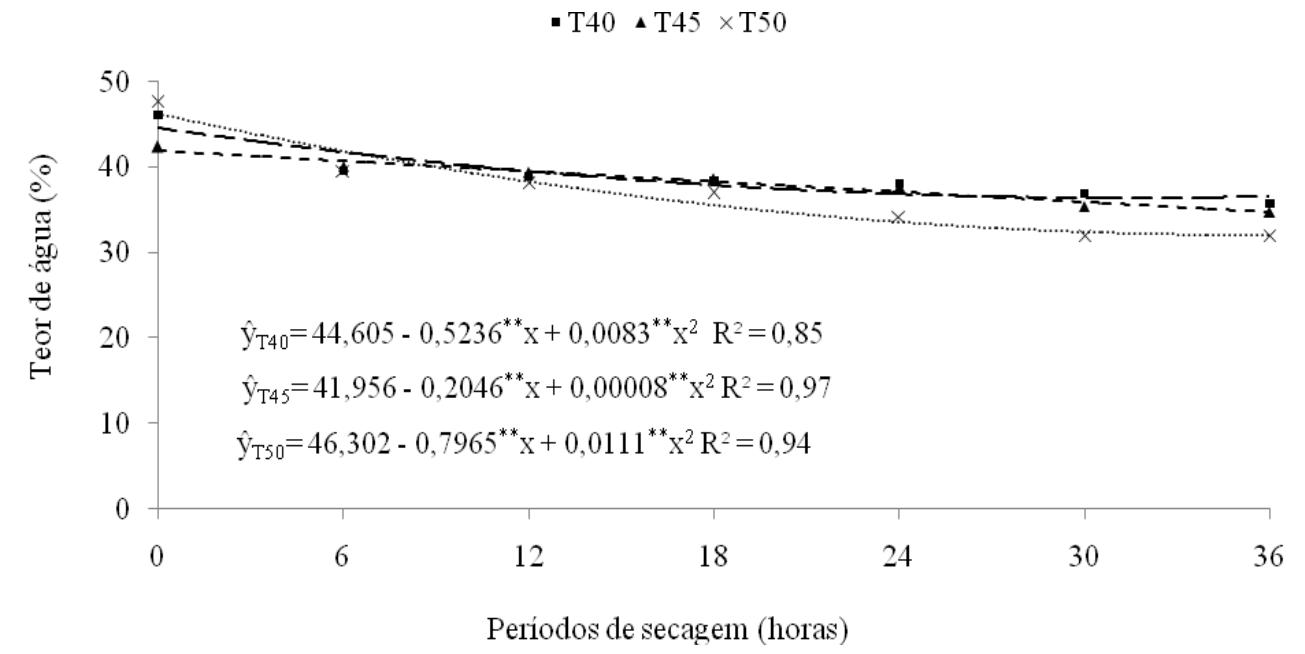

Fonte: Elaboração dos autores.

Resultados semelhantes foram verificados para o teor de água de várias espécies com sementes recalcitrantes, conforme observado em palmeira real australiana (Archontophoenix alexandrae H. Wendl and Drude), em que houve redução nas primeiras horas de secagem (ANDRADE; SCHORN; NOGUEIRA, 2005), enquanto para sementes de açaí (Euterpe oleracea Mart.) foram necessárias 480 horas de secagem para reduzir o teor de água de $43 \%$ para $11 \%$ (NASCIMENTO; NOVEMBRE; CICERO, 2007). De forma similar, Alves et al. (2008b) verificaram a necessidade de um período de secagem de 120 horas (temperatura e umidade relativa do ar em torno de $27^{\circ} \mathrm{C}$ e $45 \%$, respectivamente) para reduzir o teor de água de $T$. esculenta de 40 para $37 \%$. Para sementes de mangaba (Hancornia speciosa Gomes) o teor de água reduziu de 56 para $31 \%$ após 72 horas, chegando a $12 \%$ após 144 horas de secagem em temperatura ambiente de $24,5^{\circ} \mathrm{C}$ (SANTOS et al., 2010).

A secagem das sementes de T. esculenta, nas três temperaturas testadas proporcionou redução na porcentagem de emergência das plântulas (Figura 2), no entanto, as maiores reduções ocorreram a partir de 12 horas de secagem, sendo a redução de 17, 43 e 49\%, cujo teor de água crítico (quando há redução acentuada na germinação e/ou emergência 
de plântulas) situa-se em torno de $38 \%$, sendo a emergência máxima de 46\%. A emergência de plântulas foi drasticamente inibida quando as sementes foram secas a $40^{\circ} \mathrm{C}$ durante 36 horas e a $45^{\circ} \mathrm{C}$ com 30 horas. Dessa forma, percebese que as sementes são sensíveis a desidratação, uma vez que o teor de água ainda era elevado, sendo de $36,34 \mathrm{e} 32 \%$ nas temperaturas de 40 , 45 e $50^{\circ} \mathrm{C}$, respectivamente. A provável causa da ausência de emergência nos períodos de secagem de 30 e 36 horas foi a ocorrência de danos nos seus tecidos vitais, a exemplo do embrião, o que reduz drasticamente a emergência das plântulas após os períodos de secagem.

Figura 2. Emergência de plântulas de T. esculenta oriundas de sementes submetidas a diferentes períodos e temperaturas de secagem.

- $\mathrm{T} 40 \Delta \mathrm{T} 45 \times \mathrm{T} 50$

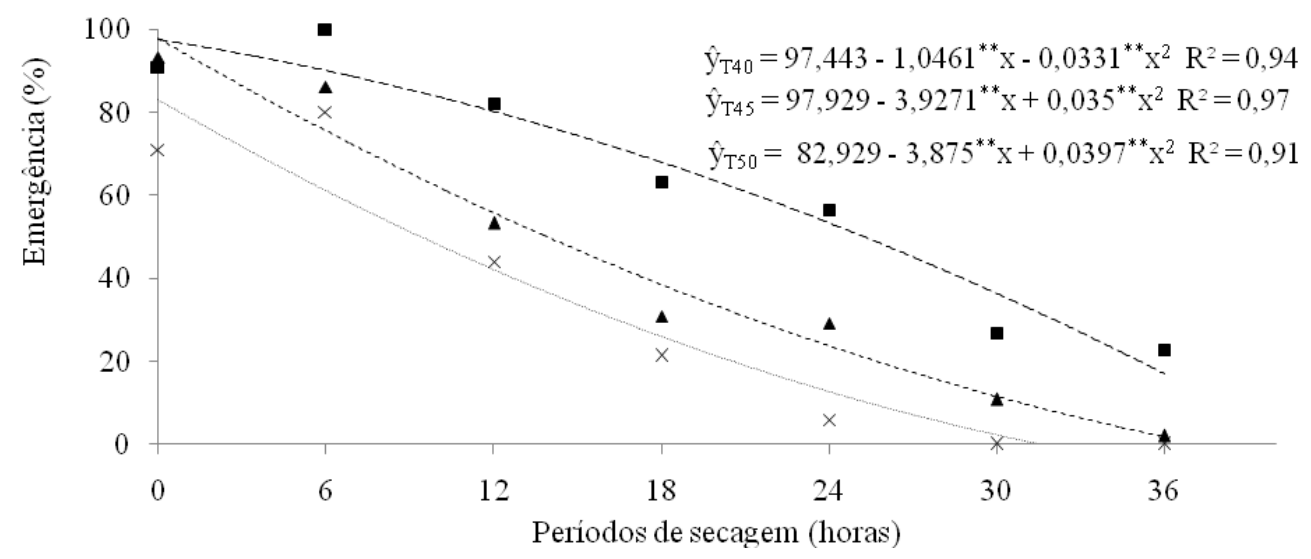

Fonte: Elaboração dos autores.

Conforme constatado na presente pesquisa, a secagem também foi prejudicial a sementes de outras espécies com comportamento recalcitrante, a exemplo das de abricó-de-macaco (Couroupita guyanensis Aubl.), que quando postas em estufa ventilada a $50^{\circ} \mathrm{C}$, por um período superior a uma hora e meia também houve prejuízos à sua germinação (CUNHA et al., 1990). De forma similar, a secagem também proporcionou redução na germinação de sementes de mangaba (H. speciosa) (OLIVEIRA; VALIO, 1992; SALOMÃO; SANTOS; MUNDIM, 2004; BARROS et al., 2010).

Para os dados referentes a primeira contagem de emergência de plântulas oriundas de sementes submetidas à secagem nas temperaturas de 40, 45 e $50^{\circ} \mathrm{C}$ não houve ajuste a modelos de regressão polinomial, cujos valores médios foram de 15, 10 e $8 \%$, respectivamente (Figura 3 ).

Para o índice de velocidade de emergência de plântulas (Figura 4) verificou-se a mesma tendência de comportamento da emergência de plântulas, com redução significativa na velocidade de emergência a partir de seis horas, que foi de $26 \%$ nas temperaturas de 40 e $45^{\circ} \mathrm{C}$ e de $30 \%$ à temperatura de $50^{\circ} \mathrm{C}$, respectivamente. Quando atingiu 12 horas de secagem observaram-se reduções de 47 , 49 e $56 \%$, para as temperaturas de 40,45 e $50^{\circ} \mathrm{C}$, respectivamente, chegando a valores nulos às 36 horas de secagem. 
Figura 3. Índice de velocidade de emergência de plântulas de $T$. esculenta oriundas de sementes submetidas a diferentes períodos e temperaturas de secagem.

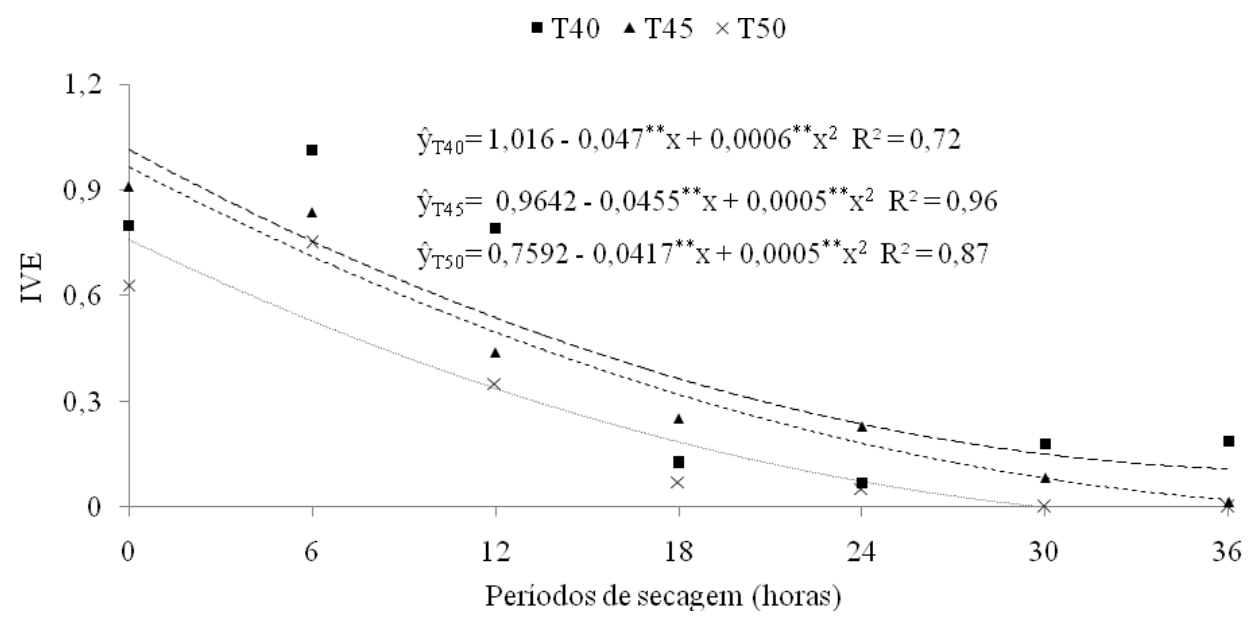

Fonte: Elaboração dos autores.

Figura 4. Primeira contagem de emergência de plântulas de T. esculenta oriundas de sementes submetidas a diferentes períodos e temperaturas de secagem.

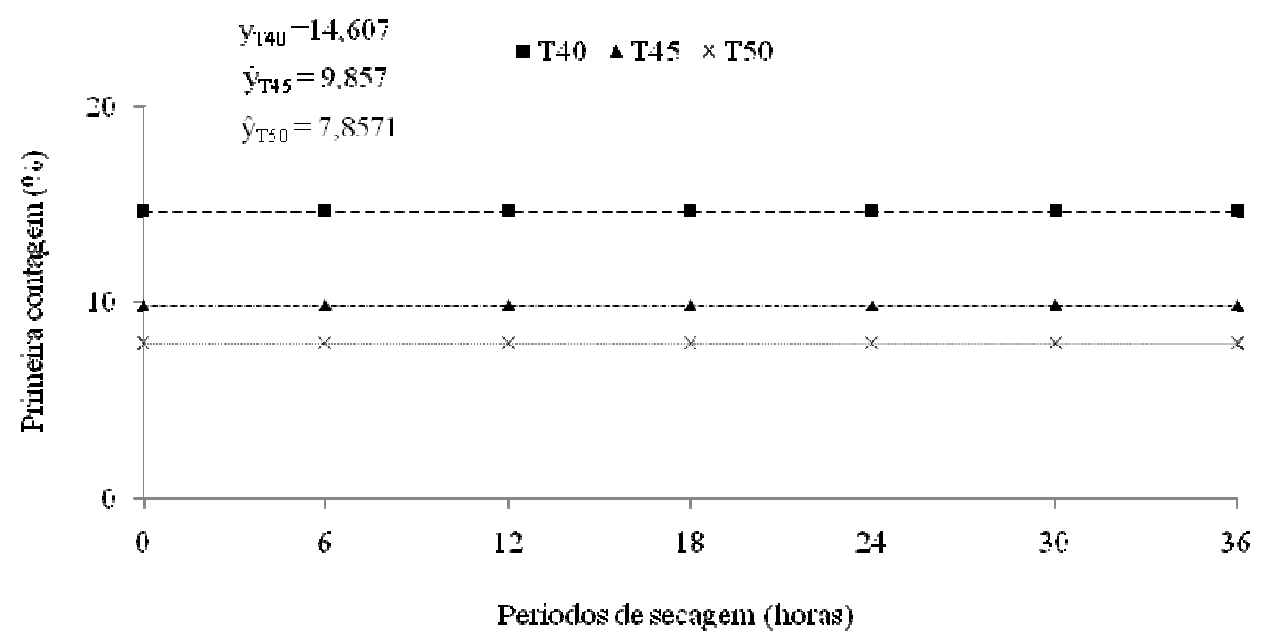

Fonte: Elaboração dos autores.

Independente da temperatura de secagem a velocidade de emergência foi afetada intensamente pelos períodos de secagem, fazendo com que a emergência de plântulas ocorresse lentamente quando a temperatura de $50^{\circ} \mathrm{C}$ foi usada. Resultados semelhantes foram obtidos por Alves et al. (2008a) quando constataram que as sementes de ingá do brejo (Inga vera Willd.) tiveram seu vigor afetado quando submetidas à secagem, enquanto em sementes de
T. esculenta, Alves et al. (2008b) observaram que as maiores velocidade de emergência $(1,41)$ foram obtidas com o período de 44 horas de secagem a sombra (ambiente de laboratório a $27^{\circ} \mathrm{C}$ ).

Em sementes de outras espécies também sensíveis a desidratação, os períodos de secagem de 0 e 20 horas não causaram redução significativa na velocidade de geminação das sementes de palmito jussara (E. edulis Mart.), no entanto o teste foi 
sensível em detectar redução do vigor das sementes a medida que se aumentaram os períodos de secagem (MARTINS et al., 2009). Para mangabeira (Hancornia speciosa Gomes), Santos et al. (2010) observaram que o maior índice de velocidade de emergência $(0,62)$ foi obtido quando as sementes foram submetidas à secagem em ambiente de laboratório $\left(24,5^{\circ} \mathrm{C}\right)$ por 21 horas.

Pelos dados referentes ao comprimento de plântulas de T. esculenta observa-se que quando as sementes foram postas para secar na temperatura de $40^{\circ} \mathrm{C}$ não houve ajuste a nenhum modelo de regressão polinomial, cujo valor médio foi de 21,38 $\mathrm{cm}$ (Figura 5). Quando a secagem foi na temperatura de $45^{\circ} \mathrm{C}$ constatou-se redução linear no comprimento das plântulas emergidas, sendo constatado valor de 13,78 cm no período de 18 horas de secagem, cuja redução foi de $34 \%$ em relação ao controle; com relação a secagem na temperatura de $50^{\circ} \mathrm{C}$, o comprimento máximo de plântulas $(21,06 \mathrm{~cm})$ foi obtido após 1,36 horas. Dessa forma percebe-se que a secagem, provavelmente comprometeu os tecidos das sementes, principalmente de reserva, resultando em menor transferência para o crescimento das plântulas, fato também verificado em plântulas de açaizeiro (E. oleracea), cujo comprimento decresceu significativamente quando houve redução no teor de água das sementes após secagem em câmara seca a temperatura de $30 \pm 2{ }^{\circ} \mathrm{C}$ (MARTINS et al., 1999; NASCIMENTO; NOVEMBRE; CICERO, 2007).

Figura 5. Comprimento de plântulas de $T$. esculenta oriundas de sementes submetidas a diferentes períodos e temperaturas de secagem.

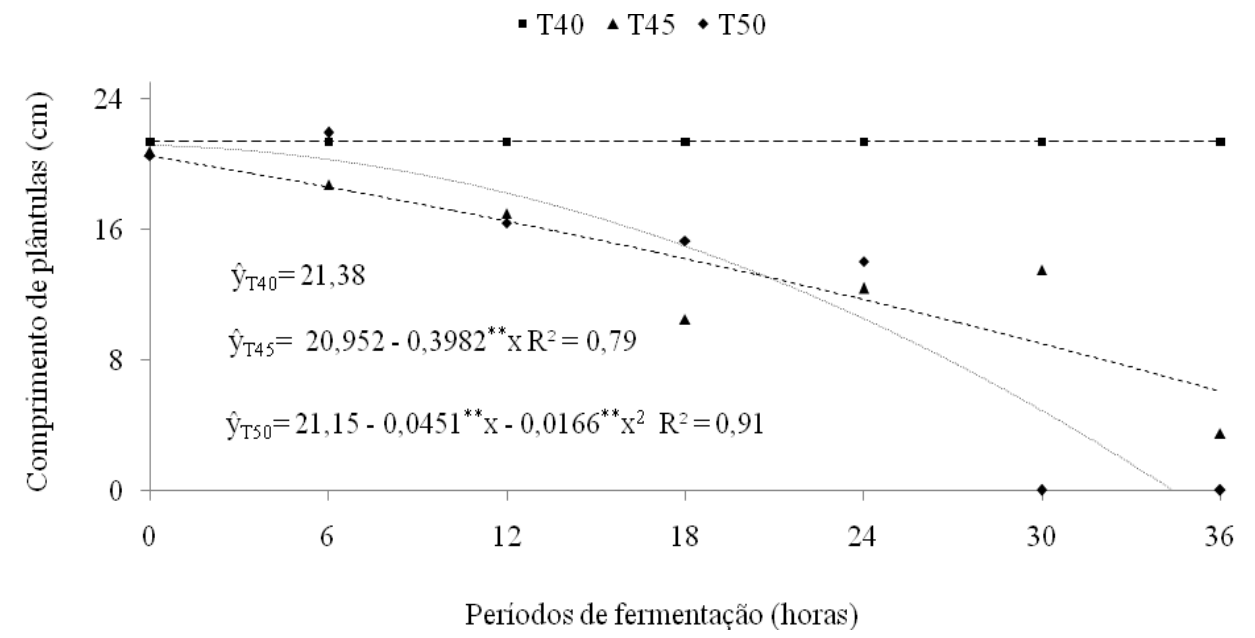

Fonte: Elaboração dos autores.

A secagem de sementes recalcitrantes também foi prejudicial ao comprimento das plântulas resultantes, a exemplo da T. esculenta, cujos maiores valores do comprimento da raiz primária $(15,79 \mathrm{~cm})$ e da parte aérea $(11,29 \mathrm{~cm})$ foram alcançados com sementes submetidas a secagem por 35 e 40 horas, respectivamente (ALVES et al., 2008b). O maior comprimento do epicótilo $(5,25 \mathrm{~cm})$ de plântulas de pitanga (Eugenia uniflora L.) foi obtido com sementes secas a sombra a temperatura de $27,5^{\circ} \mathrm{C}$ por 72 horas (SENA et al., 2010). Em sementes de mangaba (H. speciosa) Santos et al. (2010) constataram um aumento do comprimento da parte aérea $(4,96 \mathrm{~cm})$ após secagem das sementes (temperatura de $24,5^{\circ} \mathrm{C}$ ) por 56 horas.

Analisando-se os dados de massa seca de plântulas de T. esculenta (Figura 6) observou-se redução linear à medida que se prolongou o período 
de secagem das sementes na temperatura de $45^{\circ} \mathrm{C}$, sendo a taxa de redução de $33 \%$ após 18 horas de secagem. Quando as sementes foram submetidas a secagem nas temperaturas de 40 e $50^{\circ} \mathrm{C}$ os dados da massa seca não se ajustaram a modelos de regressão polinomial, com valores médios de 0,11 e $0,08 \mathrm{~g}$, respectivamente. Alves et al. (2008b) constataram que a secagem de sementes de $T$. esculenta por um período de 33 horas foi responsável pelo máximo conteúdo de massa seca de plântulas $(0,079$ g), enquanto que o da parte aérea foi de 0,229 g após secagem das sementes por 50 horas em laboratório.

Figura 6. Massa seca de plântulas de T. esculenta oriundas de sementes submetidas a diferentes períodos e temperaturas de secagem.

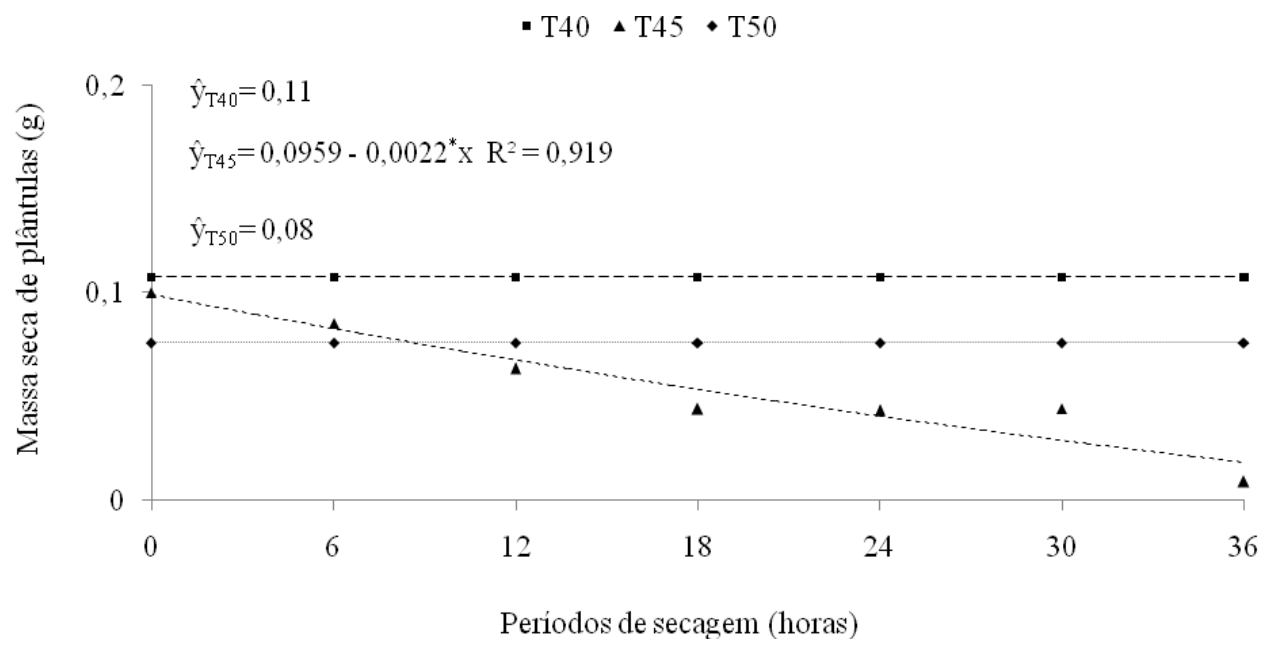

Fonte: Elaboração dos autores.

No presente trabalho o teor de água das sementes após seis horas de secagem foi em torno de $41 \%$, ocorrendo uma redução para $38 \%\left(50^{\circ} \mathrm{C}\right)$ após 12 horas, pois a maior parte dos testes de vigor utilizados indicam que a secagem por períodos superiores a 12 horas tiveram efeitos prejudiciais no vigor das sementes, comprovando sua sensibilidade à dessecação, uma vez que períodos prolongados de secagem causaram efeitos prejudiciais a qualidade fisiológica das mesmas.

\section{Conclusões}

A secagem das sementes de Talisia esculenta Radlk deve ser realizada nas temperaturas de 40 e $45^{\circ} \mathrm{C}$ por um período inferior a seis horas, quando atingem $41 \%$ de umidade.

\section{Agradecimentos}

Os autores agradecem ao Conselho Nacional de Desenvolvimento Científico e Tecnológico (CNPq), pelo apoio financeiro a essa pesquisa, e ao Centro de Ciências Agrárias da Universidade Federal da Paraíba (CCA/UFPB) e Programa de Pós-Graduação em Agronomia (CCA/UFPB) pelo apoio técnico e científico.

\section{Referências}

ALVES, E. U.; GUEDES, R. S.; PONTUAL, H. U.; GONÇALVES, E. P.; SILVA, K. B. Influência da secagem na germinação e vigor de sementes de Inga vera Willd. In: CONGRESSO DE PESQUISA E INOVAÇÃO DA REDE NORTE NORDESTE DE EDUCAÇÃO TECNOLÓGICA (III CONNEPI), 3., 2008, Fortaleza. Anais... Fortaleza: CONNEPI, 2008a. p. 1-6. 
ALVES, E. U.; SILVA, K. B.; BRUNO, R. L. B.; ALVES, A. U.; CARDOSO, E. A.; GONÇALVES, E. P.; BRAZ, M. S. S. Comportamento fisiológico de sementes de pitombeira [Talisia esculenta (St. Hil) Radlk] submetidas à desidratação. Revista Brasileira de Fruticultura, Jaboticabal, v. 30, n. 2, p. 509-516, 2008b.

ANDRADE, A. C. S.; PEREIRA, T. S. Comportamento de armazenamento de sementes de palmiteiro (Euterpe edulis Mart.). Pesquisa Agropecuária Brasileira, Brasília, v. 32, n. 10, p. 987-991, 1997.

ANDRADE, R. R.; SCHORN, L. A.; NOGUEIRA, A. C. Tolerância à dessecação em sementes de Archantophoenix alexandrae Wendl. and Drude (palmeira real australiana). Ambiência, Guarapuava, v. 1, n. 2, p. 279-288, 2005.

BARBEDO, C. J.; MARCOS FILHO, J. Tolerância à dessecação de sementes. Acta Botanica Brasilica, São Paulo, v. 12, n. 2, p. 145-164, 1998.

BARROS, D. I.; BRUNO, R. L. A.; NUNES, H. V.; MENDONÇA, R. M. N.; PEREIRA, W. E. Tecnologia de sementes de mangaba (Hancornia speciosa Gomes). Revista Acta Tecnológica - Revista Científica, Monte Castelo, v. 5, n. 1, p. 31-43, 2010.

BILIA, D. A. C.; MARCOS-FILHO, J.; NOVEMBRE, A. D. C. L. Desiccation tolerance and seed storability of Inga uruguensis (Hook. Et Arn.). Seed Science and Technology, Zürich, v. 27, n. 1, p. 77-89, 1999.

BRASIL. Ministério da Agricultura, Pecuária e Abastecimento. Regras para análise de sementes. Secretaria de Defesa Agropecuária. Brasília: MAPA/ ACS, 2009. 395 p.

CUNHA, R.; SANTANA, C. A. F.; CARDOSO, M. A.; PEREIRA, T. S. Secagem, desinfestação e germinação de sementes de Couroupita guyanensis Aubl. Revista Brasileira de Sementes, Brasília, v. 12, n. 2, p. 74-79, 1990.

FARRANT, J. M.; PAMMENTER, N. W.; BERJAK, P. Recalcitrance - a current assessment. Seed Science and Technology, Zurich, v. 16, n. 1, p. 155-166, 1988.

GUARIM NETO, G.; SANTANA, S. R.; SILVA, J. V. B. Repertório botânico da pitombeira (Talisia esculenta (St. -Hil.) Radlk. - Sapindaceae). Acta Amazonica, Manaus, v. 33, n. 2, p. 237-242, 2003.

HARTMANN, H. T.; KESTER, D. E.; DAVIES JUNIOR, F. T.; GENEVE, R. L. Plant propagation: principles and practices. 7. ed. New Jersey: Prentice Hall, 2001. 880 p.

HONG, T. D.; ELLIS, R. H. Optimum air-dry seed storage environments for arabica coffee. Seed Science and Technology, Zürich, v. 20, n. 3, p. 547-560, 1992.
KERMODE, A. R. Regulatory mechanisms involved in the transition from seed development to germination. Critical Reviews in Plant Sciences, Boca Raton, v. 9, n. 2, p. 155-195, 1990.

LORENZI, H.; MATOS, F. J. Plantas medicinais no Brasil: nativas e exóticas cultivadas. Nova Odessa: Instituto Plantarum, 2006. 512 p.

MAGUIRE, J. D. Speed of germination aid in selection and evaluation for seeding emergence and vigor. Crop Science, Madison, v. 2, n. 2, p. 76-177, 1962.

MARTINS, C. C.; MACHADO, C. G.; NAKAGAWA, J.; OLIVEIRA. S. S. C. Tamanho e secagem de sementes de palmeira Jussara sobre a germinação e o vigor. Caatinga, Mossoró, v. 22, n. 2, p. 117-120, 2009.

MARTINS, C. C.; NAKAGAWA, J.; BOVI, M. L. A.; STANGUERLIM, H. Teores de água crítico e letal para sementes de açaí (Euterpe oleracea Mart. - Palmae). Revista Brasileira de Sementes, Londrina, v. 21, n. 1, p. 125-132, 1999.

NAKAGAWA, J. Testes de vigor baseados no desempenho das plântulas. In: KRZYZANOWSKI, F. C.; VIEIRA, R. D.; FRANÇA NETO, J. B. (Ed.). Vigor de sementes: conceitos e testes. Londrina: ABRATES, 1999. p. 2-21.

NASCIMENTO, W. M. O.; NOVEMBRE, A. D. L. C.; CICERO, S. M. Consequências fisiológicas da dessecação em sementes de açaí (Euterpe oleracea Mart.). Revista Brasileira de Sementes, Pelotas, v. 29, n. 2, p. 38-43, 2007.

NEDEVA, D.; NIKOLOVA, A. Desiccation tolerance in developing seeds. Bulgarian Journal of Plant Physiology, Sofia, v. 23, n. 3-4, p. 100-113, 1997.

OLIVEIRA, L. M. Q.; VALIO, I. F. M. Effects of moisture content on germination of seeds of Hancornia speciosa Gom. (Apocynaceae). Annals of Botany, London, v. 69, n. 1, p. 1-5, 1992.

PAMMENTER, N. W.; BERJAK, P. A review of recalcitrant seed physiology in relation to desiccation tolerance mechanisms. Seed Science Research, Wallingford, v. 9, n. 1, p. 13-37, 1999.

PRITCHARD, H. W. Water potential and embryonic axis viability in recalcitrant seeds of Quercus rubra. Annals of Botany, London, v. 67, n. 1, p. 43-49, 1991.

SALOMÃO, A. N.; SANTOS, I. R. I.; MUNDIM, R. C. Conservação, manejo e uso de sementes de Hancornia speciosa Gomes (Apocynaceae). Brasília: EMBRAPA Recursos Genéticos e Biotecnologia, 2004. 26 p. (Documentos, 126). 
SANTOS, P. C. G.; ALVES, E. U.; GUEDES, R. S.; SILVA, K. B.; CARDOSO, E. A.; LIMA, C. R. Qualidade de sementes de Hancornia speciosa Gomes em função do tempo de secagem. Semina: Ciências Agrárias, Londrina, v. 31, n. 2, p. 343-352, 2010.

SENA, L. H. M.; MATOS, V. P.; FERREIRA, E. G. B. S.; SALES, A. G. F. A.; PACHECO, M. V. Qualidade fisiológica de sementes de pitangueira submetidas a diferentes procedimentos de secagem e substratos parte 2. Revista Brasileira de Engenharia Agrícola e Ambiental, Campina Grande, v. 14, n. 4, p. 405-411, 2010.
SILVA, K. B.; ALVES, E. U.; BRUNO, R. L. A.; SANTOS, S. S.; BARROSO, L. M. Tolerância à dessecação de sementes de Cinnamomum zeylanicum Ness. Semina: Ciências Agrárias, Londrina, v. 33, n. 2, p. 587-594, 2012.

VIEIRA, F. A.; GUSMÃO, E. Biometria, armazenamento e emergência de plântulas de Talisia esculenta Radlk. (Sapindaceae). Ciência e Agrotecnologia, Lavras, v. 32, n. 4, p. 1073-1079, 2008. 